\title{
The thermo-sensitive sensilla coeloconica of leaf-cutting ants (Atta vollenweideri)
}

\author{
Markus Ruchty ${ }^{\mathrm{a}, *}$, Roberto Romani ${ }^{\mathrm{b}}$, Linda S. Kuebler ${ }^{\mathrm{a}, \mathrm{d}}$, Sara Ruschioni ${ }^{\mathrm{b}, \mathrm{c}}$, Flavio Roces ${ }^{\mathrm{a}}$, \\ Nunzio Isidoro ${ }^{c}$, Christoph J. Kleineidam ${ }^{\mathrm{a}}$ \\ a Department of Behavioral Physiology and Sociobiology, Biozentrum, University of Würzburg, 97074 Würzburg, Germany \\ ${ }^{\mathrm{b}}$ Dipartimento di Scienze Agrarie e Ambientali, Perugia University, 06121 Perugia, Italy \\ ${ }^{\mathrm{c}}$ Dipartimento Scienze Ambientali e delle Produzioni Vegetali, Marche University, 60131 Ancona, Italy \\ ${ }^{\mathrm{d}}$ Evolutionary Neuroethology, Max-Planck-Institut for Chemical Ecology, Hans-Knöll-Straße 8, 07745 Jena, Germany
}

Keywords:

Radiant heat

Convective heat

Peg-in-pit sensillum

Cold-sensitive neuron

Sensory adaptation

Thermal orientation

\begin{abstract}
A B S T R A C T
Social insects show a variety of temperature-guided behaviors. Depending on whether heat reaches the sensillum via air movements (convective heat) or as radiant heat, specific adaptations of thermosensitive sensilla are expected. In the present study the morphology and the physiology of thermosensitive peg-in-pit sensilla (S. coeloconica) of the leaf-cutting ant Atta vollenweideri were investigated. S. coeloconica are located predominantly in a single cluster on the apical antennomere, and connect to the outside through a small aperture. The sensory peg is double-walled, embedded in a chamber and innervated by three unbranched dendrites. Using tungsten electrodes, activity of the sensory neurons was measured. In most cases, the neuron with the largest spike amplitude responds to changes in air temperature (convective heat) as well as to radiant heat. In response to a drop in air temperature, the neuron shows a phasic-tonic response followed by a complete adaptation within 1 min (cold-sensitive neuron). Based on their morphology and physiology, it is suggested that the S. coeloconica are involved in the recently described thermal orientation behavior of $A$. vollenweideri leaf-cutting ants.
\end{abstract}

\section{Introduction}

The antennae are the most prominent sensory organs of insects. They are equipped with a vast number of different sensilla. The majority of sensilla serves an odor-receptive function; others are used for mechano-, temperature- or humidity-reception. Sensilla are classified based on morphological characters, which are expected to reflect an adaptation to improve stimulus reception. For example, the long trichoid sensilla for pheromone reception in the male silk moth, Bombyx mori, have a large surface area, and are arranged like combs on the antennae such that pheromone molecules are effectively captured from an air current. Another amazing morphological adaptation has been described for thermo-sensitive sensilla of fire beetles (genus Melanophila), which can detect and approach forest fires from a distance of up to $12 \mathrm{~km}$ to encounter mates and lay eggs into freshly-burned wood (Evans, 1964; Schmitz and Bleckmann, 1998). The thermo-sensitive sensilla contain a specialized structure (cuticular sphere) which absorbs IR

\footnotetext{
* Corresponding author. Tel.: +49931 888 4336; fax: +49931 8884309.

E-mail addresses: ruchty@biozentrum.uni-wuerzburg.de (M. Ruchty),rromani@ unipg.it (R. Romani), lkuebler@ice.mpg.de (L.S. Kuebler), sara.ruschioni@hotmail.it (S. Ruschioni),roces@biozentrum.uni-wuerzburg.de (F. Roces), n.isidoro@univpm.it (C.J. Isidoro), kleineidam@biozentrum.uni-wuerzburg.de (C.J. Kleineidam).
}

radiation and acts as an outer pressure vessel. Inside the sphere a microfluidic component generates an increase in internal pressure which then causes a compression of the dendritic tip of a mechanoreceptor (Vondran et al., 1995; Schmitz and Bleckmann, 1997; Schmitz et al., 1997, 2007; Müller et al., 2008).

Information about the thermal environment is crucial for the reproductive success of fire beetles, but it is also of paramount importance for social insects which have the ability to manipulate the thermal environment within the nests to improve brood development. A number of different temperature-guided behaviors emphasize the significance of thermoreception in the life of ants, wasps and bees (social Hymenoptera). However, surprisingly little is known about the underlying sensory mechanisms.

In most insect species, thermo-sensitive neurons are located in peg-in-pit sensilla, often combined with two hygro-sensitive neurons forming a sensory triad (Waldow, 1970; Tichy, 1979; Altner et al., 1981; Yokohari, 1983; Altner and Loftus, 1985). In social insects such an organization has been described for the S. coelocapitula of the honeybee Apis mellifera. Other thermo-sensitive neurons have been found in S. ampullacea and S. coeloconica (Lacher, 1964; Dumpert, 1978; Yokohari, 1983; Kleineidam and Tautz, 1996). In the mosquito (Aedes aegypti), two antagonistic thermo-sensitive neurons (cold-warm neurons) have been found within one sensillum (Davis and Sokolove, 1975). Even the 
combination of thermo- and chemo-sensitive neurons occurs in several insect species (Altner et al., 1977, 1981; Davis, 1977; Hansson et al., 1996).

However, the peg-in-pit morphology does not unambiguously predict the housing of a thermo-sensitive neuron. For instance, in search of a thermo-sensitive neuron in the S. coeloconica of the moth, B. mori, solely chemo-sensitive neurons have been found (Boeckh, 1967; Pophof, 1997; Pophof et al., 2005). And furthermore, thermo-sensitive neurons occur in sensilla without peg-in-pit morphology (Loftus, 1966, 1968; Altner et al., 1977; Loftus and Corbière-Tichané, 1981).

In order to elucidate a structure-function relationship, both fine structure and the gross morphology of the sensilla are equally important. While morphological data on thermo-sensitive sensilla are available across different insect orders, data on their fine structure are fragmentary. Fine structural analysis of thermosensitive sensilla in several insect species indicate that some coldsensitive neurons have a highly lamellated outer dendritic segment (Corbière and Bermond, 1972; Corbière, 1974; Corbière-Tichané, 1977; Altner and Loftus, 1985; Steinbrecht, 1989). In Hymenoptera, data on the fine structure of peg-in-pit sensilla are available only for the S. ampullacea but are lacking for both, S. coeloconica and S. coelocapitula (Kleineidam et al., 2000).

Leaf-cutting ants (genus Atta and Acromyrmex) are evolutionary derived eusocial insects with pronounced size polymorphism, highly organized colonies and complex nest architecture (Weber, 1966). For instance, a colony of Atta vollenweideri controls its nest climate with the help of a passive nest ventilation mechanism, and the construction of structures such as ventilation tunnels and turrets (Kleineidam and Roces, 2000; Kleineidam et al., 2001). Inside the nest, brood and fungus translocation is used as a shortterm response to track favorable conditions (Roces and Kleineidam, 2000; Bollazzi and Roces, 2002). Outside the nest, leaf-cutting ants are able to learn the location of a food source using radiant heat as an orientation cue (Kleineidam et al., 2007). Due to the different physical properties of the thermal stimuli (e.g. convective heat and radiant heat) used for different temperature-guided behaviors, specific adaptations of the thermo-sensitive sensilla are expected.

In the present study, the thermo-sensitive S. coeloconica of the leaf-cutting ant $A$. vollenweideri were investigated in detail regarding their arrangement on the apical antennomere, as well as their morphology. The neuronal activity of one of the three associated sensory neurons of the S. coeloconica was examined electrophysiologically. Finally, the functional morphology is discussed as a possible adaptation to the reception of either convective or radiant heat

\section{Materials and methods}

\subsection{Animals}

Workers of A. vollenweideri were obtained from a laboratory colony collected by Bollazzi M. and Geissler O. in 2002 at the Reserva Ecológica El Bagual, Formosa, Argentina. The colony was reared at the Biozentrum, University of Würzburg at $25^{\circ} \mathrm{C}$ and $50 \%$ relative humidity in a $12 \mathrm{~h} / 12 \mathrm{~h}$ photoperiod, and fed mainly with leaves of privet (Ligustrum vulgaris) and dog rose (Rosa canina). For the experiments, only medium sized workers from the feeding site were collected, thus it is assumed that only foragers were investigated.

\subsection{Morphology (SEM)}

The cuticular structures of the flagellum and the S. coeloconica were investigated by scanning electron microscopy (SEM). The flagellum was either fixed overnight in phosphate-buffered $4 \%$ formaldehyde (PBS, pH 7.2), or the apical antennomere was sectioned obliquely with a razor blade followed by tissue removal with warm $3 \mathrm{M} \mathrm{KOH}$-solution and 10 min cleansing in an ultrasonic bath. All specimens were dehydrated in a graded ethanol series (50\%, 70\%, 80\%, 90\% 95\% and 100\%; 10 min each) and Aceton (100\% for $10 \mathrm{~min}$ ), and critical point-dried (CPD030, Balzers Union, Liechtenstein). The specimens were glued onto SEM-supports, gold-palladium-coated (MED010, Balzers Union, Liechtenstein) and examined with a scanning electron microscope (DSM962, Zeiss, Germany). From each investigated worker, only one flagellum was analyzed (independent measures of single specimens).

The S. coeloconica are clustered in the dome-shaped tip of the antenna. Looking at the surface of the flagellum, only small apertures are visible and these belong either to S. coeloconica or to $\mathrm{S}$. ampullacea. The length and the width of each sensillum aperture were measured in 7 specimens and their area calculated. The distances of all apertures of the 11th antennomere to the antennal tip were measured for 2 specimens.

\subsection{Fine structure (TEM)}

For transmission electron microscopy (TEM) observations, 13 workers were anaesthetized in $\mathrm{CO}_{2}$, immersed in ice-cold $2.5 \%$ glutaraldehyde in $0.1 \mathrm{M}$ cacodylate buffer $+5 \%$ glucose, $\mathrm{pH}$ 7.2-7.3. In order to facilitate fixative penetration, the apical antennomeres were detached immediately from the rest of the antennae and the specimens were fixed at $4{ }^{\circ} \mathrm{C}$ for about $2 \mathrm{~h}$. After rinsing overnight in cacodylate buffer, the specimens were post-fixed in $1 \%$ osmium tetroxide at $4{ }^{\circ} \mathrm{C}$ for about $1 \mathrm{~h}$ and rinsed in the same buffer. Dehydration in a graded ethanol series was followed by embedding in an Epon-Araldite mixture (Fluka, Sigma-Aldrich; Buchs, Switzerland), using propylene oxide as bridging solvent. Thin (90$120 \mathrm{~nm}$ ) sections were taken with a Diatome ${ }^{\circledR}$ diamond knife on an ultramicrotome (L.K.B. Nova, Bromma, Sweden) and mounted on collodium-coated 50 mesh grids. Finally, after staining with uranyl acetate (20 $\mathrm{min}$, room temperature) and lead citrate (5 min, room temperature), the sections were observed with a TEM (Philips EM 208, FEI Company, The Netherlands). Digital pictures (1376 × 1032 pixels, 8 bit grayscale, uncompressed Tiff files) were taken using a high-resolution digital camera (Megaview III SIS, Olympus, Japan).

\subsection{Electrophysiology}

In search for thermo-sensitive neurons, the associated receptor cells of S. coeloconica were investigated by extracellular recordings of neuronal activity. Workers were mounted on a plastic holder with adhesive tape and the scapus was glued onto the holder with whiteout correction fluid (Tipp-Ex, Bic, France). Under visual control and at a magnification of $400 \times$ (Leitz microscope equipped with NPL-Fluotar L25/0.35, Leitz, Germany), an electrolytically sharpened tungsten electrode was superficially inserted into the cuticle next to the chamber of a S. coeloconicum using a manual micromanipulator (HS-6, Märzhäuser, Germany). In order to achieve a good signal to noise ratio, the reference electrode was inserted deep into the flagellum in close vicinity to the recording electrode. Recordings were band-pass filtered $(60 \mathrm{~Hz}-3 \mathrm{kHz})$ and amplified $1000 \times$ (Neuroprobe Amplifier 100, A-M-Systems, USA and VBF8, Kemo, Great Britain). The electrical noise was significantly reduced using an additional digital filter (Humbug, Quest Scientific, Canada). Data were digitized at a sampling rate of $12 \mathrm{kHz}$ (IDAC-4-USB, Synthec, Netherlands) and stored for analysis (AutoSpike 32, Syntech, Netherlands) on a PC.

During all physiological experiments, an ambient airflow (flow rate $1.5 \mathrm{l} / \mathrm{min}$ ) was continuously channeled via a glass tube $(2 \mathrm{~cm}$ in diameter, at a distance of $1 \mathrm{~cm}$ from the antenna) and blown over the preparation (continuous airflow). 
The responses of the thermo-sensitive neurons to convective stimuli were investigated by using a second (stimulus) airflow. A metal tube $(1 \mathrm{~cm}$ in diameter, at a distance of $1 \mathrm{~cm}$ from the antenna) was positioned opposite to the tube providing the continuous airflow. Air temperature in both, the continuous- and the stimulus-airflow was measured continuously with thermocouples (NiCr-Ni, Typ K, Conrad Electronics, Germany), logged on a PC, and controlled by heat exchangers close to the outlet of the airflows. The heat exchangers could be heated or cooled via two silicon tubes which were connected with two water baths (DC1, Haake, Germany). This setup allowed us to generate convective stimuli with temperatures ranging from $12^{\circ} \mathrm{C}-45^{\circ} \mathrm{C}$. A stimulus controller (CS-01, Synthec, Netherlands) was used to switch on the stimulus airflow for either $10 \mathrm{~s}$ or $10 \mathrm{~min}$, resulting in rapid changes in air temperature at the antenna.

To study the physiological adaptation of the thermo-sensitive neurons in response to prolonged stimulation, a step change from room temperature $\left(24^{\circ} \mathrm{C}\right.$, continuous airflow) to the stimulus airflow with either $6^{\circ} \mathrm{C}$ above room temperature $\left(30^{\circ} \mathrm{C}\right)$ or $6^{\circ} \mathrm{C}$ below room temperature $\left(18^{\circ} \mathrm{C}\right)$ was used, while simultaneously recording the neuronal activity. The adaptation process was described by measuring the mean instant frequency (bin size $1 \mathrm{~s}$ ) once every minute.

The responses of the thermo-sensitive neurons to radiant heat (infrared radiation) were investigated by using a broad-band IRemitter (Wavelength 0.4-11.2 $\mu \mathrm{m}$, SVF 360-8 M, Laser components, Germany,). The IR-emitter was mounted on a micromanipulator at a distance of $3 \mathrm{~cm}$ above the antenna. For IR stimulation, the IRemitter was powered with $2.6 \mathrm{~W}$ and pulsed with a frequency of $0.25 \mathrm{~Hz}$ using a frequency generator (PM 5133 function generator, Phillips, Netherlands). The calculated radiation power at the preparation was $133 \mathrm{~mW} / \mathrm{cm}^{2}$. In order to exclude the influence of convective heat, e.g. from the heated air around the emitter, a temperature controlled airflow (continuous airflow) was blown over the preparation throughout the experiments.

Statistical analysis was performed using Statistica 7.1 (Statsoft, Tulsa, USA) and data were plotted with Origin 8 (OriginLab, USA).

\section{Results}

\subsection{Morphology (SEM)}

The SEM investigations revealed that peg-in-pit sensilla are located predominantly on the apical (11th) antennomere. The sensory peg embedded in the pit connects to the outside through a small round or oval aperture (Fig. 1A). The apertures, located on the latero-ventral side of the flagellum, belong either to the $\mathrm{S}$. coeloconica or the S. ampullacea. In 7 investigated flagella, 9-16 peg-in-pit sensilla were found on the apical antennomere, compared to only $0-2$ apertures on the 7 th-10th antennomeres. The size of the apertures on the apical antennomere varied considerably, ranging from 0.7 to $2.3 \mu \mathrm{m}$ in length diameter $(n=102)$, whereas on the more proximal antennomeres their size ranged only from 1.3 to $2.3 \mu \mathrm{m}(n=24)$. For two additional apical antennomeres, the size of the aperture (length and width) and its distance to the antennal tip were measured. Two size-classes of apertures, with larger apertures located more distally than small apertures, were found (Fig. 2). The internal view of the apical antennomere revealed a cluster of S. coeloconica located distally of a cluster of S. ampullacea (Fig. 1C). This arrangement indicates that the large apertures $\left(>0.5 \mu \mathrm{m}^{2}\right)$ belong to the S. coeloconica and the small apertures belong to the S. ampullacea. The aperture sizes found on the more proximal antennomeres indicate that these also belong to S. coeloconica rather than to S. ampullacea. Subsequently, the $S$. coeloconica could be discriminated from S. ampullacea solely by examining the antenna from the outside.
The aperture of the S. coeloconica opens into a chamber containing the sensory peg inside. The chamber has a width of about $6 \mu \mathrm{m}$ and a height of about $8 \mu \mathrm{m}$, the peg is $4-5 \mu \mathrm{m}$ long (Fig. 1B). At the cup-shaped base, the peg is formed of 4-6 finger-like ridges that split into two before they fuse at the tip. The $\mathrm{S}$. coeloconica are almost completely embedded in the thick antennal cuticle such that the cup-shaped base and the perpendicularly standing peg inside are inclined towards the antennal tip. The peg's tip faces right to the aperture, and all S. coeloconica of the apical cluster seem to face into the same direction (Fig. 1D).

\subsection{Fine structure (TEM)}

Longitudinal (Fig. 3A) and serial (Figs. 3B-D and 4A) cross sections through the sensory peg of $S$. coeloconica were used to describe the fine structural characters. Cross sections in the middle of the peg revealed that it is double-walled (Fig. 3C). Both walls have no pores and appear to share the same cuticular structure in terms of cuticle electron density and thickness (about $50 \mathrm{~nm}$ ). The two cuticular walls define two distinct cavities, an innermost and an outermost cavity. The innermost cavity (diameter about $200 \mathrm{~nm}$ ) is filled by the densely packed outer dendritic segments of the sensory neurons and by the sensillum lymph (Fig. 3B-D). Cross sections close to the tip revealed the stellate characteristic of the sensory peg (Fig. 3B). The inner and outer wall merge towards the tip, thereby forming 8-12 sub-conical (in cross section) cuticular fingers which are separated by spoke canals. The thickness of the cuticular wall of the cuticular fingers differs, being thinner on the side facing the peg lumen (about $75 \mathrm{~nm}$ ) and thicker towards the outside (about $150 \mathrm{~nm}$ ).

The outermost cavity in the middle of the peg and within each cuticular finger is filled with electron-dense tubular-like material (Fig. 3B, C). In contrast to the cuticular fingers, at the base of the peg electron-dense tubular-like material is almost completely absent, while clusters of electron lucid vesicles (diameter ranging from 80 to $400 \mathrm{~nm}$ ) are found (Fig. 3A inset; Fig. 3D). These vesicles surround the inner cuticular wall deep into the sensillar sinus, where they are also found within the cytoplasm of the trichogen cell (Fig. 4A, B). The inner cuticular wall originates from the dendritic sheath which is formed by the thecogen cell (Fig. 4B). Since the inner wall is preserved even after $\mathrm{KOH}$ treatment, it was also observed in the SEM study (Fig. 1D).

The S. coeloconicum is innervated by three sensory neurons without variation in the number across investigated specimens ( $n=13$; several sensilla per specimen). It is noteworthy that one dendrite is always remarkably larger (diameter $1 \mu \mathrm{m}$ ) than the other two (diameter $0.5 \mu \mathrm{m}$ ) which is the case at both the outer and the inner dendritic segment level (Fig. 4A-D). The three outer dendritic segments enter the cuticular peg and extend unbranched up to the tip of the peg. The outer as well as the inner dendritic segment is surrounded by the thecogen cell which forms the inner sensillum lymph space (Fig. 4B-D). The thecogen cell has numerous microvilli and is filled with a large number of elongated mitochondria (Fig. 4B). No tubular bodies were found in the sensory neurons associated with the S. coeloconica. The fine structural characters of the S. coeloconica are summarized in the schematic drawing (Fig. 5).

\subsection{Electrophysiology}

The neuronal activity of up to three sensory neurons was recorded when the electrode was placed close to the aperture of a S. coeloconicum. The sensory neurons can easily be distinguished by the different amplitudes of the extracellular measured action potentials (spikes). In most cases, the neuron with the largest spike amplitude responds to a cold air stimulus with a phasic-tonic 

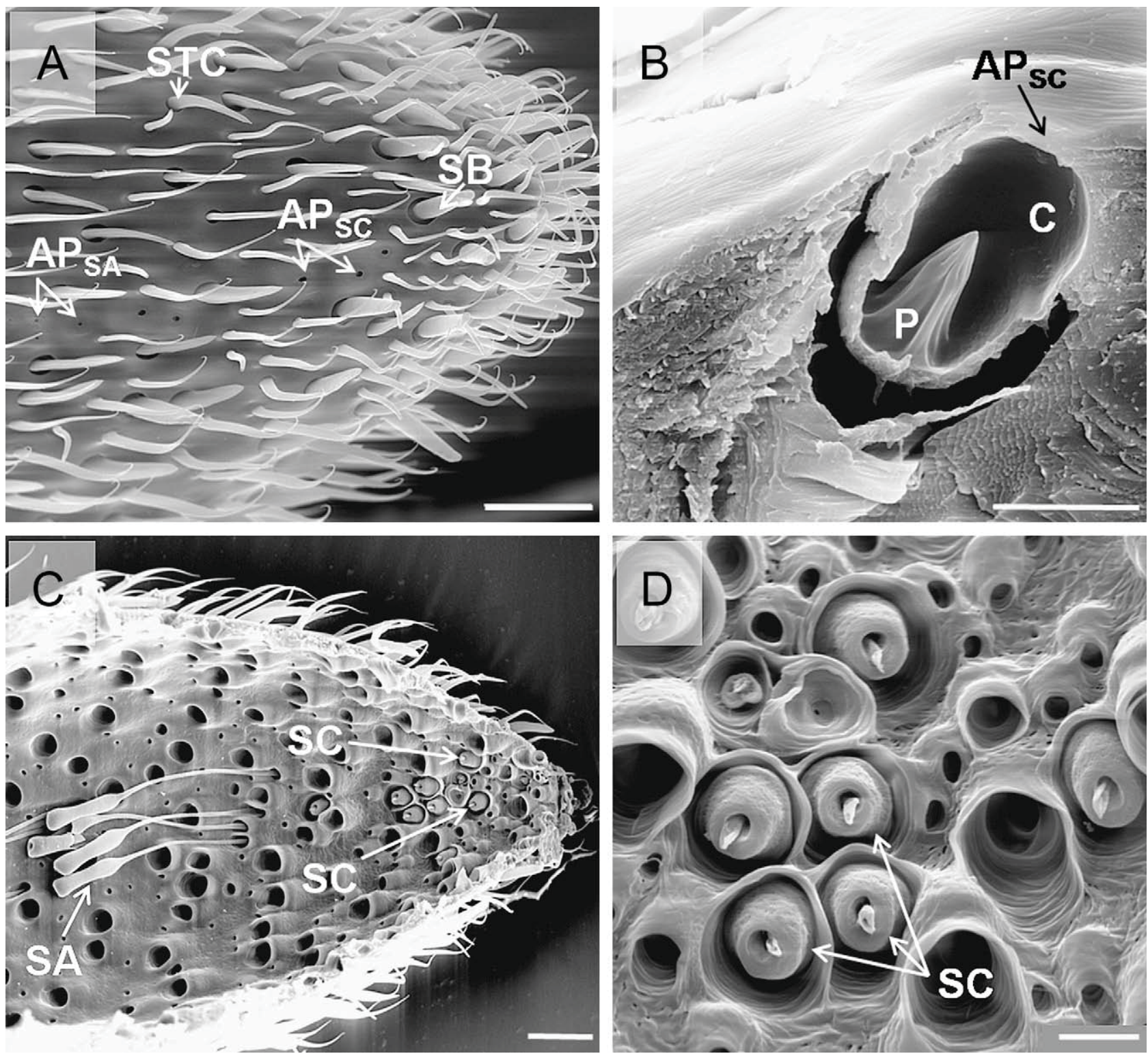

Fig. 1. Location, morphology and orientation of the S. coeloconica. A: Overview of the apical antennomere with the apertures of the S. coeloconica at the distal tip and the more proximal apertures of the S. ampullacea. B: Longitudinal section of the chamber of a S. coeloconicum with the peg inside. The aperture is cut-open. C: Internal view of the last flagellar segment with S. coeloconica and S. ampullacea. D: Orientation of a group of S. coeloconica embedded into the antennal cuticle and inclinated towards the tip of the antenna (internal view). AP, aperture of the peg-in-pit sensilla; C, chamber of a S. coeloconicum; SA, S. ampullaceum, SB, S. basiconicum; SC, S. coeloconicum; STC, S. trichodeum curvatum; P, peg of the SC; Scale bar: $20 \mu \mathrm{m}$ in A and C; $5 \mu \mathrm{m}$ in B and D.

response (Fig. 6A, B). Based on approximately 100 recordings of thermo-sensitive neurons, the neuronal activity ranges between $8 \mathrm{Imp} / \mathrm{s}$ and $140 \mathrm{Imp} / \mathrm{s}$ (peak frequency) at room temperature $\left(\mathrm{RT}=24^{\circ} \mathrm{C}\right)$.

Using a stimulus airflow (convective heat) at $11.2^{\circ} \mathrm{C}$ below the temperature of the continuous airflow, the peak frequency ranges from $177 \mathrm{Imp} / \mathrm{s}$ to $690 \mathrm{Imp} / \mathrm{s}(n=16)$ within $200 \mathrm{~ms}$ after stimulus onset. In response to an increase in air temperature $\left(\Delta \mathrm{T}=6^{\circ} \mathrm{C}\right)$ after stimulation, the thermo-sensitive neurons cease the generation of action potentials for sometimes longer than $10 \mathrm{~s}$.

Using an IR-Emitter pulsed at $0.25 \mathrm{~Hz}$, the thermo-sensitive neuron shows a reduced activity during a radiant heat stimulus of $133 \mathrm{~mW} / \mathrm{cm}^{2}$ compared to the neuronal activity when the IRemitter was turned-off (Fig. 7). Thus, radiant heat is an effective stimulus although the sensory peg is sheltered in an almost enclosed cavity. Interestingly, the response characteristic differs in comparison to the described phasic-tonic response to convective stimuli. The phasic part of the off-response to IR stimulation is reduced (Fig. 7)

In addition to warm and cold air applied with the stimulus airflow, and to radiant heat applied with the IR-emitter, an ordinary red laser pointer $(<1 \mathrm{~mW})$ and even a human finger in close vicinity to the antenna sufficed as thermal stimulus to diminish the neuronal activity of the thermo-sensitive neuron. Based on the physiological experiments, the investigated neuron of the S. coeloconica is considered as a cold-sensitive neuron.

In response to prolonged stimulation $(10 \mathrm{~min})$ with either $30^{\circ} \mathrm{C}$ or $18^{\circ} \mathrm{C}$, the cold-sensitive neuron shows complete physiological adaptation, i.e. there is no difference in neuronal activity before and after 10 min of stimulation (Fig. 8A-B) $(n=10)$. Although neuronal activity reaches $80 \mathrm{Imp} / \mathrm{s}$ (mean instant frequency, bin $1 \mathrm{~s}$ ) after onset of the cold stimulus airflow $\left(18^{\circ} \mathrm{C}\right)$, an activity comparable to pre-stimulation condition $(23 \mathrm{Imp} / \mathrm{s})$ is reached within $1 \mathrm{~min}$ (Fig. 8A). Similar recovery of the neuronal activity is observed after 


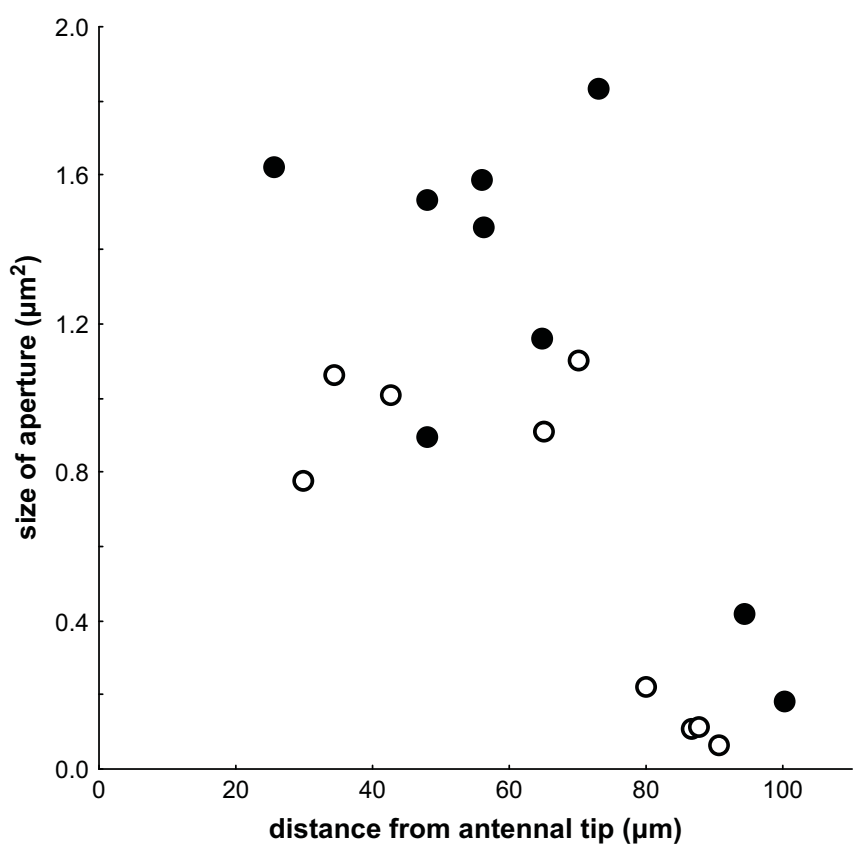

Fig. 2. Location and aperture size of peg-in-pit sensilla: Size of the aperture is related to the location of the peg-in-pit sensilla: large apertures $\left(>0.5 \mu \mathrm{m}^{2}\right)$ of the S. coeloconica are located distal compared to the small apertures $\left(<0.5 \mu \mathrm{m}^{2}\right)$ of the $\mathrm{S}$. ampullacea located more proximal. Two apical antennomeres of different workers, indicated with black and open circles, were examined.

onset of the warm stimulus airflow $\left(30^{\circ} \mathrm{C}\right)$ with an initial reduced activity $(0.7 \mathrm{Imp} / \mathrm{s})$ and an activity comparable to pre-stimulation condition within 1 min of stimulation (Fig. 8B).

\section{Discussion}

\subsection{Morphology (SEM)}

Sensilla coeloconica are peg-in-pit sensilla with a sensory peg located in a chamber connected to the environment by an aperture (Altner and Loftus, 1985). In several ant species, small apertures with similar diameters have already been described (Prellinger, 1940; Jaisson, 1970; Hashimoto, 1990). Based on the size of the aperture of different peg-in-pit sensilla, S. coeloconica and S. ampullacea can be discriminated in some ant species, e.g. Solenopsis invicta (Renthal et al., 2003) and A. vollenweideri (this study), but are indistinguishable in other species, e.g. A. sexdens (Kleineidam et al., 2000). Compared to the abundance of hair sensilla, S. coeloconica have been found in low numbers on the antenna of ants and other insects as well (Dumpert, 1972; Tominaga and Yokohari, 1982; Itoh et al., 1984; Nishikawa et al., 1985; Hashimoto, 1990; Iwasaki et al., 1995; Renthal et al., 2003).

The peg-in-pit morphology protects the sensory peg against harsh mechanical contact, for instance during antennal grooming, and probably avoids evaporative water loss and evaporative cooling (Altner et al., 1977; Shanbhag et al., 1995). Mechanical protection might be important in particular for thermo-sensitive neurons whose mechanical sensitivity has previously been described (Gödde and Haug, 1990).

\subsection{Fine structure (TEM)}

Altner et al. (1977) introduced a classification of sensilla, in order to predict the function of a sensillum based on its fine structure characters, rather than on gross morphology alone. The wall structures of the sensory pegs (single-walled or double-walled), and the type of exclusive pore structures are the major traits for classification. The combination of sensory neurons for different modalities e.g. in thermo-sensitive sensilla challenges the significance of this classification with respect to a structure-function analysis.

Across insect orders, thermo-sensitive neurons were found in sensilla with different fine structural traits, e.g. single- or doublewalled, and porous or non-porous pegs. Most often, thermo-sensitive neurons have been found in association with two hygro-sensitive neurons forming a sensory triad that consists of a moist-sensitive neuron, a dry-sensitive neuron and a cold-sensitive neuron (MDC-triad) (Altner and Prillinger, 1980; Altner and Loftus, 1985). MDC-triads have been described mostly for single-walled peg-in-pit sensilla with a non-porous peg on an inflexible socket (Waldow, 1970; Altner et al., 1977, 1981, 1983; Yokohari, 1978; Tichy, 1979; Altner and Prillinger, 1980; Yokohari, 1981; Tominaga and Yokohari, 1982; Nishikawa et al., 1985; Haug, 1986; Ameismeier and Loftus, 1988; Gödde and Haug, 1990; Zimmermann, 1992). For the honeybee, the MDC-triad has been described for S. coelocapitula with a putative single-walled structure (Yokohari et al., 1982; Yokohari, 1983).

However, the MDC-triad has also been found in sensilla with a double-walled peg, e.g. in the cockroach Periplaneta americana (Altner et al., 1977). For the honeybee, a thermo-sensitive neuron has been found in the S. coeloconica, which is also probably a doublewalled sensillum, but unfortunately information on detailed fine structure and the attribution of physiological data to this sensillum are inconclusive (Slifer and Sekhon, 1961; Lacher, 1964).

As shown in this study, the $S$. coeloconica of $A$. vollenweideri are double-walled sensilla housing a cold-sensitive neuron. Doublewalled sensilla with spoke channels commonly house chemosensitive neurons (Steinbrecht, 1997) and in case of the locust (Locusta migratoria), a thermo-chemo-sensitive combination has been described (Altner et al., 1981). The two neurons beside the cold-sensitive neuron in the S. coeloconica of A. vollenweideri did not respond to any of the thermal stimuli tested, and whether these are chemo-sensitive remains unresolved.

Lamellation of the outer dendritic segment is a trait that has been described for some cold-sensitive neurons, e.g. in the MDCtriad of the stick insect (Carausius morosus) (Altner et al., 1978). Lamellated outer dendritic segments also have been described for the 'black hair sensillum' of the cave beetle (Speophyes lucidulus) which carries two antagonistic thermo-sensitive neurons (coldand warm-sensitive neurons) (Loftus and Corbière-Tichané, 1981). In contrast, exclusively chemo-sensitive sensilla with lamellated outer dendritic segments of sensory neurons have been described e.g. on the palps of Pieris rapae (Lee et al., 1985). Thus, lamellation of the outer dendritic segment of a sensory neuron does not necessarily predict its function as cold-sensitive neuron.

In the $S$. coeloconica of $A$. vollenweideri, electron lucid vesicles were found at the base of the sensory peg, close to the outermost cavity. Vesicles with similar electron density have been reported in the sensillum lymph of double-walled sensilla of several insect species (Altner et al., 1977; Ameismeier, 1985; Cribb and Jones, 1995). For the chemo-sensitive S. coeloconica described in B. mori, the content of these vesicles has been discussed as precursor of the electron-dense filaments in the lumen of the cuticular fingers. However, their possible function for sensory transduction remained elusive (Hunger and Steinbrecht, 1998).

\subsection{Electrophysiology}

A cold-sensitive neuron was identified in the S. coeloconica by extracellular recordings of neuronal activity. Following a drop in temperature, the cold-sensitive neurons respond with increased neuronal activity (phasic-tonic response), irrespective whether cold air or radiant heat (off-response) was used as stimulus. 

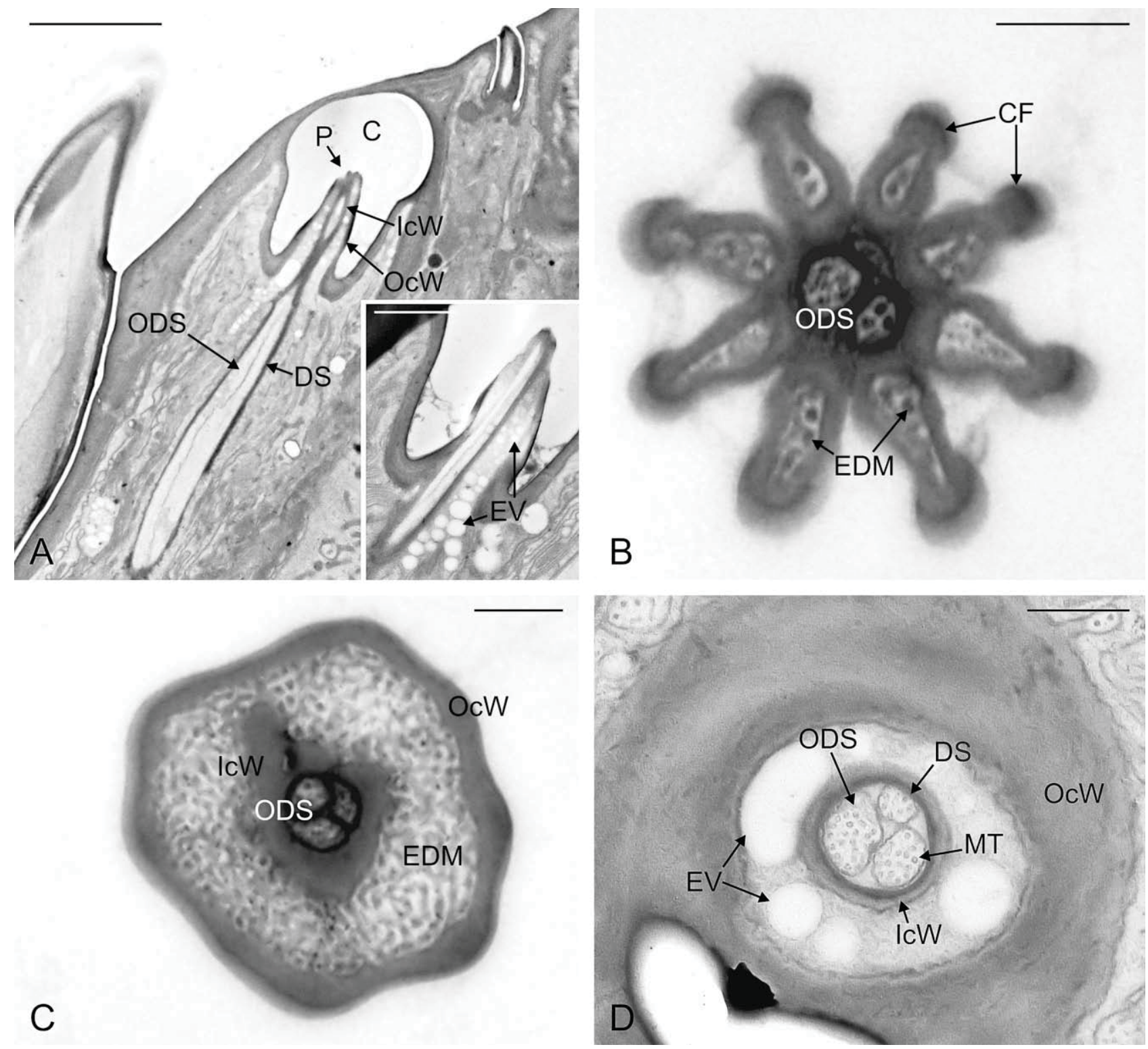

Fig. 3. TEM micrographs of sensilla coeloconica in A. vollenweideri. A: Longitudinal section of a S. coeloconicum showing the cuticular chamber with the peg and the outer dendritic segments enveloped by the dendritic sheath. At the peg level the inner and the outer cuticular wall are visible. B-D: Cross sections of a sensillum coeloconicum close to the tip (B) and to the base (D). In B the stellate arrangement of the cuticular fingers and in $C$ and $D$ the double-walled structure of the sensillum are visible. The internal lumen of the peg is filled with electron-dense material in the distal half (B and C), while electron lucid vesicles are found in the proximal half (D, inset in A). Scale bar: A: $5 \mu$ m; inset: $2 \mu$ m; B, C: $250 \mathrm{~nm}$; D: $500 \mathrm{~nm}$. C, chamber of a S. coeloconicum; CF, cuticular fingers; DS, dendritic sheath; EDM, electron-dense material; EV, electron lucid vesicles; IcW, inner cuticular wall; MT, microtubules; OcW, outer cuticular wall; ODS, outer dendritic segment; P, peg.

Cold-sensitive neurons with a phasic-tonic response characteristic are widespread in insects (Lacher, 1964; Loftus, 1968; Tichy, 1979; Ameismeier, 1985; Nishikawa et al., 1992; Merivee et al., 2003; Must et al., 2006a,b).

Due to the chemo-physical properties of air, any change in air temperature goes along with a change in relative humidity. The use of a heat exchanger implies that besides heat also the relative humidity of the air is manipulated. It is argued that the measured responses of the cold-sensitive neurons were specific to temperature, and not associated to the differences in relative humidity of the air used for stimulation. Two lines of indirect evidence support this view. First, radiant heat is unlikely to noteworthily influence the humidity of the continuous air blown over the preparation, and was shown to be effective as thermal stimulus. Second, a very basic experiment using human breath emphasized the specificity of the response. The neurons always responded with increased neuronal activity to cold air (and increased relative humidity) but with a decreased neuronal activity to human breath (warm air and increased relative humidity; data not shown). This result also suggests that humidity has little influence on the response of the investigated cold-sensitive neurons, an interaction that has been shown for the thermo-sensitive neurons of the stick insect, $\mathrm{Ca}$ rausius morosus, and a cave beetle (Tichy, 1978, 2007; Loftus and Corbière-Tichané, 1981).

A remarkable result of this study is the sensitivity of the coldsensitive neurons to radiation emitted, e.g., from an IR-emitter, a laser pointer, or fingertips. It has been shown by several authors that the sensitivity of cold-sensitive neurons to radiant stimuli is low or negligible (Davis and Sokolove, 1975; Gingl and Tichy, 2001), and the peg-in-pit morphology has been discussed as a feature that leads to a reduced IR-sensitivity (Gingl et al., 2005).

The phasic part of the response is reduced or even absent in response to stimuli generated with the IR-Emitter as compared to the response to convective stimuli. This conspicuous difference in 

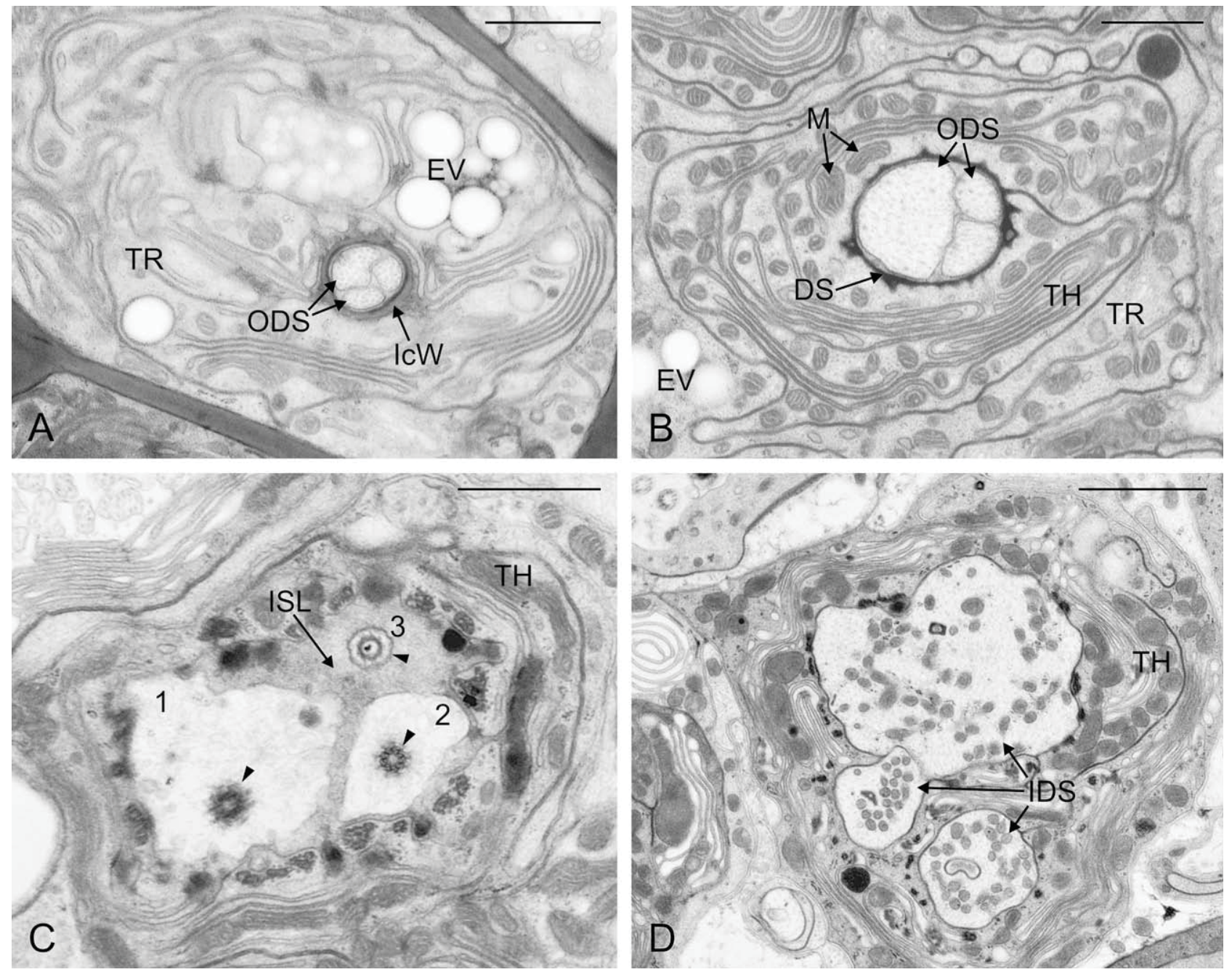

Fig. 4. TEM micrographs of the cellular components of the S. coeloconicum. A: Cross section through the proximal end of the inner cuticular wall. At this level, three outer dendritic segments are clearly visible, as well as clusters of electron lucid vesicles produced by the trichogen cell. B: Cross section of the three outer dendritic segments encircled by the dendritic sheath. The bundle of outer dendritic segments is surrounded by the thecogen cell. The trichogen cell is also visible, as well as a small cluster of electron lucid vesicles. C: Cross section of the three dendrites at the level of the ciliary segments. Neuron 1 and 2 are sectioned at the level of the basal bodies (arrowheads), while neuron 3 is sectioned more distally at the ciliary collar level (arrowhead). The dendrites are surrounded by an inner sensillum lymph space. D: Inner dendritic segments of the three sensory neurons surrounded by the thecogen cell. One of the dendrites is remarkably larger than the others. Scale bar: A-C: $1 \mu \mathrm{m}$; D: $2 \mu \mathrm{m}$. DS, dendritic sheath; EV, electron lucid vesicles; IcW, inner cuticular wall; IDS, inner dendritic segment; ISL, inner sensillum lymph space; M, mitochondria; ODS, outer dendritic segment; TR, trichogen cell; TH, thecogen cell.

response characteristics is probably due to the slow passive cooling of the IR-emitter filament after switch-off. The neuronal response to rapid loss in radiant heat, e.g. during antennal scanning movements in front of a warm object might be more pronounced than that measured in the present experiments.

Several studies on pyrophilous beetles and flat bugs of the genus Aradus showed that morphologically specialized sensilla house warm-sensitive neurons with a phasic response characteristic upon IR stimulation (Schmitz and Bleckmann, 1997, 1998; Schmitz et al., 1997, 2000a,b,2002; Schmitz and Trenner, 2003; Müller et al., 2008). Besides these highly adapted sensilla, warm-sensitive neurons have been rarely described in other insect species. Such neurons have only been identified in larvae of cave beetles and in blood sucking arthropods, and in most cases they are associated with a cold-sensitive neuron in the same sensillum (Davis and Sokolove, 1975; Loftus and Corbière-Tichané, 1981; Hess and Loftus, 1984, 1985; Gingl et al., 2005).

The cold-sensitive neuron of the S. coeloconica in A. vollenweideri shows rapid adaptation to prolonged stimulation. Unfortunately, cold-sensitive neurons in the honeybee were not tested under prolonged stimulation (Lacher, 1964), so that comparative data for other Hymenoptera are lacking. A comparable response characteristic as found in A. vollenweideri was recently described for cold-sensitive neurons in a cave beetle (Must et al., 2006b). Adaptation to continuous stimulation is a common property in sensory systems and has been well described for olfactory neurons (Kaissling et al., 1987). Sensory adaptation increases the working range in which changes in intensities can be measured but reduces the ability to measure absolute intensities. Thus, the cold-sensitive neurons of $A$. vollenweideri are tuned to track rapid changes in convective and radiant heat at different ambient temperatures.

\subsection{Sensory transduction}

The sensory transduction mechanism of thermal stimuli in the investigated S. coeloconica is still unknown. However, two different transduction mechanisms have been discussed for various other thermo-sensitive neurons. First, mechano-sensitive transduction has been described for highly specialized thermo-sensitive sensilla in buprestid beetles and in a flat bug (Vondran et al., 1995; Schmitz and Bleckmann, 1997; Schmitz et al., 2007; Müller et al., 2008).

Second, absorption of thermal energy at the membrane of the sensory neuron has been discussed to directly lead to an opening of ion channels (Gödde and Haug, 1990). Across animal clades, the 


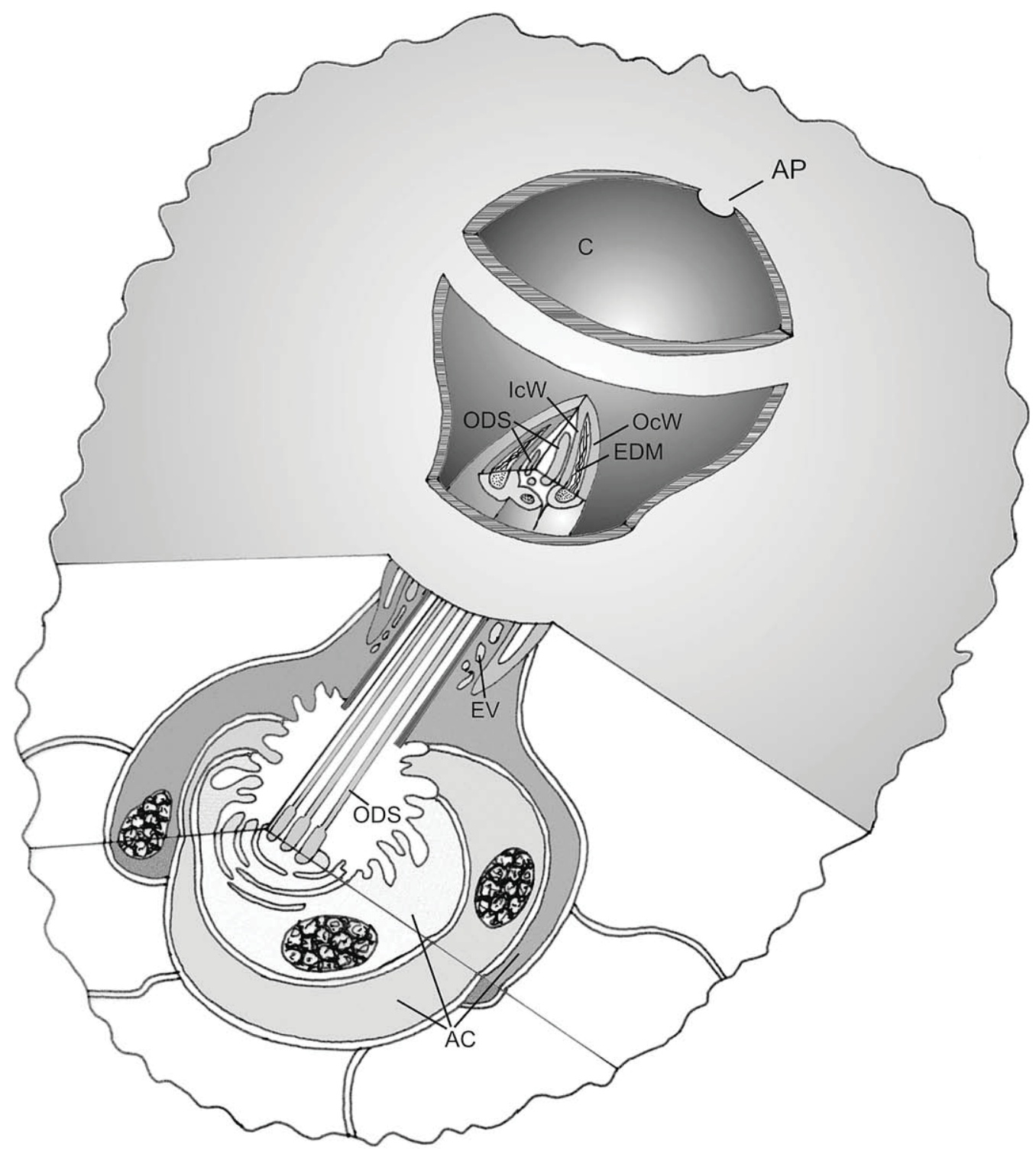

Fig. 5. Schematic 3-dimensional reconstruction (not in scale) of a S. coeloconicum of A. vollenweideri. AC, auxiliary cells; AP, aperture; C, chamber; EDM, electron-dense material; IcW, inner cuticular wall; OcW, outer cuticular wall; ODS, outer dendritic segment; EV, electron lucid vesicles.

occurrence of thermo-sensitive ion channels of the Transient Receptor Potential family (TRP-family) is highly conserved (McKemy, 2007). These channels either respond to heat and capsaicin (McKemy et al., 2002) or cold and menthol (Rosenzweig et al., 2005). Drosophila larvae lacking a specific TRP channel showed an impairment of the thermo-tactic behavior implying a specific role of TRP channels for the thermal sense of insects. It remains to be shown whether ion channels of the TRP-family are involved in the sensory transduction of thermal stimuli in the investigated cold-sensitive neurons.

\subsection{Functional morphology of S. coeloconica for thermoreception}

Based on the ground bauplan of insect sensilla, the most basic organization is found in mechano-sensitive sensilla (Keil, 1997). Although the origin of the S. coeloconica described in the present study is unknown, morphological characters indicate derived traits not found in mechano-sensitive sensilla. All traits found in a given sensillum might be constrained by its evolutionary origin, and additionally shaped by evolution to meet the function of any of the associated sensory neurons. The S. coeloconica of A. vollenweideri appear to be a good example illustrating the interdependency of origin, adaptation and multi-function. Based on the abundance of thermo-sensitive neurons found in peg-in-pit sensilla, the general morphology of the S. coeloconica in A. vollenweideri is probably an adaptation for thermoreception. In contrast, a double-walled sensory peg is a rare trait described for thermo-sensitive sensilla and suggests that the two physiologically undescribed sensory neurons of the sensillum are chemo-sensitive.

The functional significance of the pit suggests a protection against mechanical stress, and the shield with the small aperture might reduce evaporation from the peg. The low impact of changing humidity on the response of the cold-sensitive neuron is likely brought about by the almost closed chamber within the antennal cuticle. In addition, rapid changes of air temperature (convective stimuli) might be attenuated due to the enclosure of the sensory peg, thereby acting as a low-pass filter. However, this idea remains to be investigated.

Radiant heat proved to be an effective stimulus for the coldsensitive neuron, and it is argued that the shield has probably little impact on IR-reception. For infrared radiation of 3- $\mu \mathrm{m}$ wavelength, Schmitz et al. (2007) estimated a penetration depth of approximately 


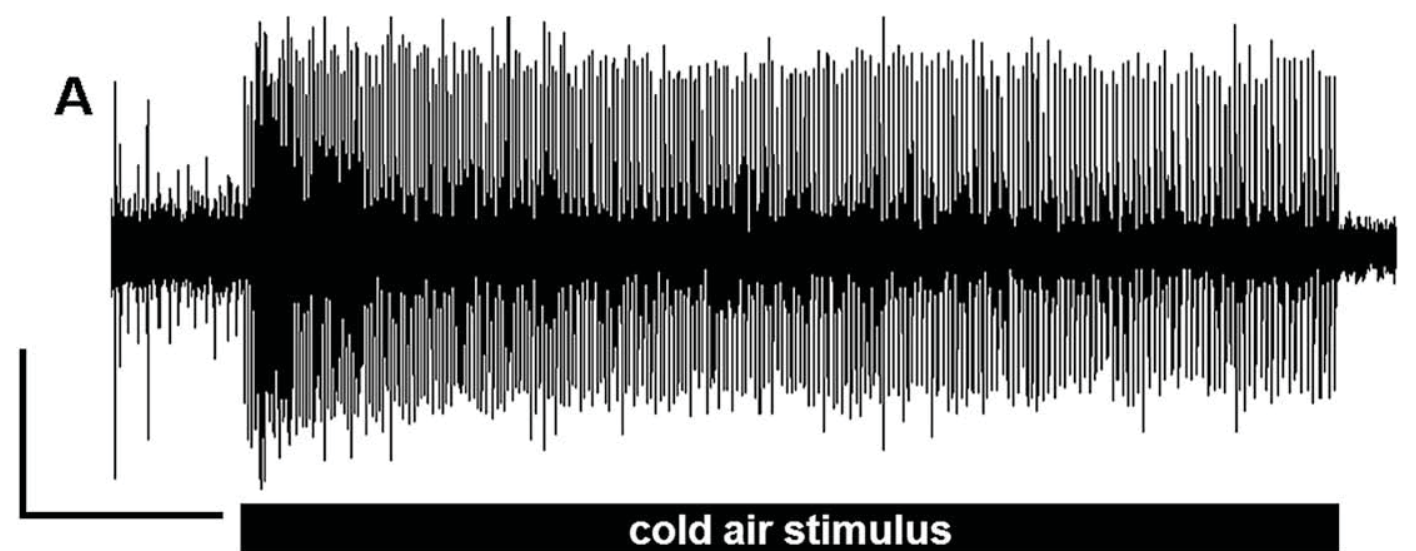

B

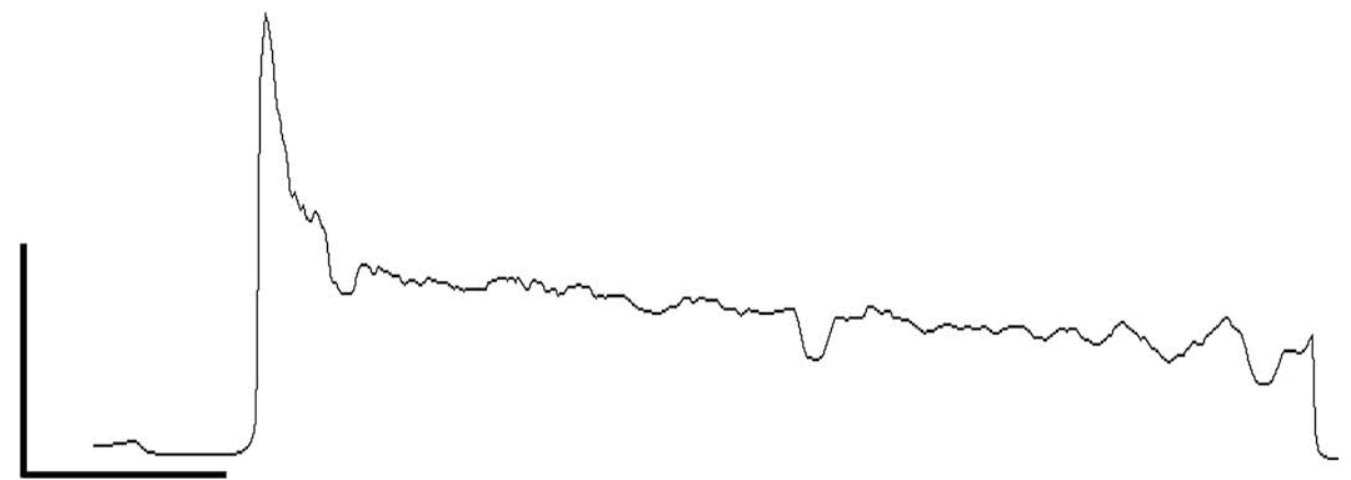

Fig. 6. Response of a thermo-sensitive neuron to a drop in air temperature of $11.2^{\circ} \mathrm{C}$. A: After stimulus onset, the neuron responded with a phasic-tonic increase in activity, thus qualifying as a cold-sensitive neuron. Scale bar: horizontal: $2 \mathrm{~s}$; vertical: $2 \mathrm{mV}$. B: Instant frequency (reciprocal of the time between two spikes) shows two distinct phases of the response. An initial phasic response is followed by a tonic but adapting response. Scale bar: horizontal: 2 s; vertical: $100 \mathrm{Imp} / \mathrm{s}$.

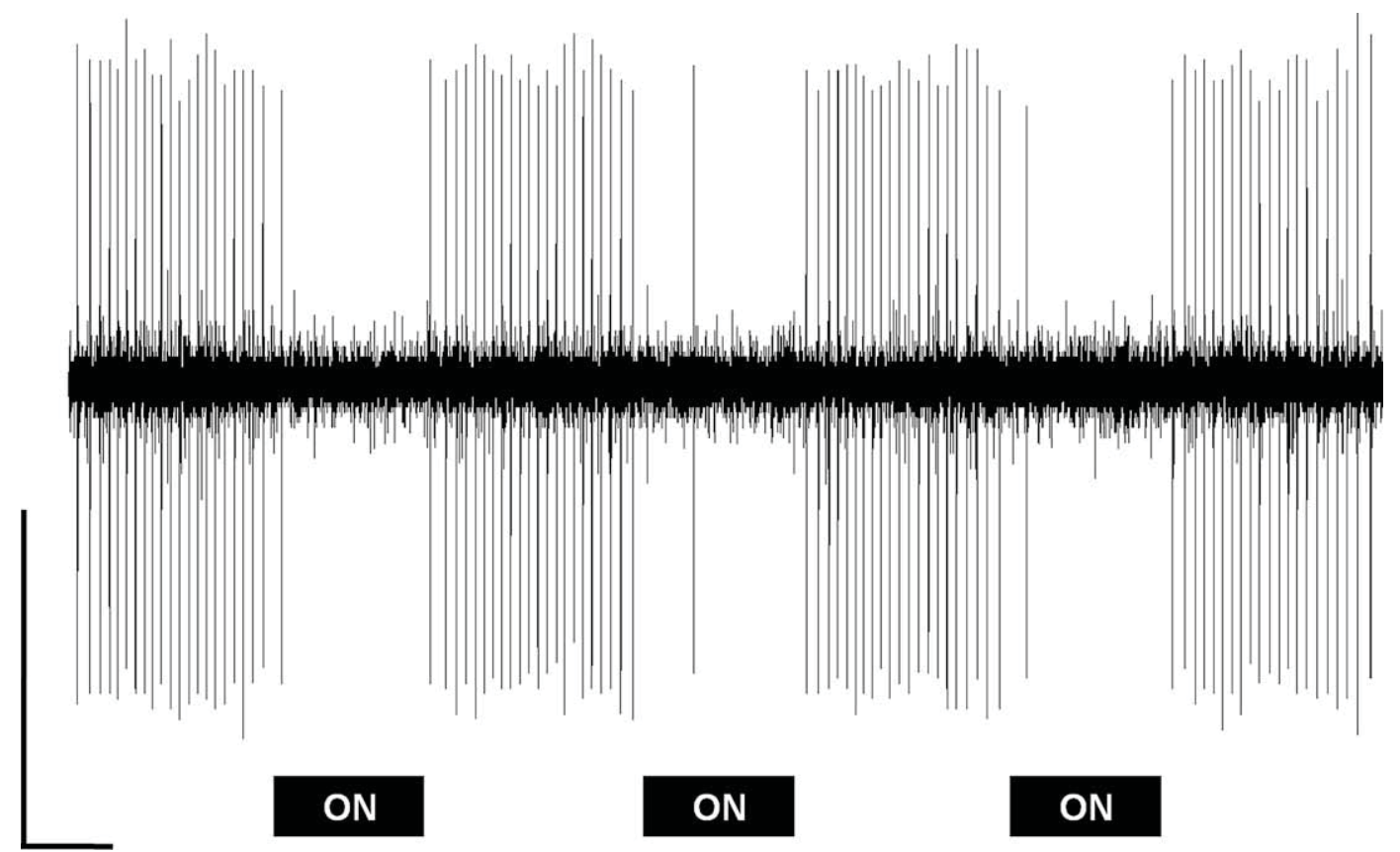

Fig. 7. Response of a cold-sensitive neuron to IR stimulation. Immediately after stimulus onset (IR-emitter, $133 \mathrm{~mW} / \mathrm{cm}^{2}$ ) the neuronal activity ceased. The mean instant frequency dropped from $11 \mathrm{Imp} / \mathrm{s}$ to almost zero during IR stimulation. Compared to stimulation with a convective stimulus (Fig. 6), the neuron showed a different response characteristic, lacking a phasic response after the cessation of IR stimulation. Scale bar: horizontal: $2 \mathrm{~s}$; vertical: $4 \mathrm{mV}$. 

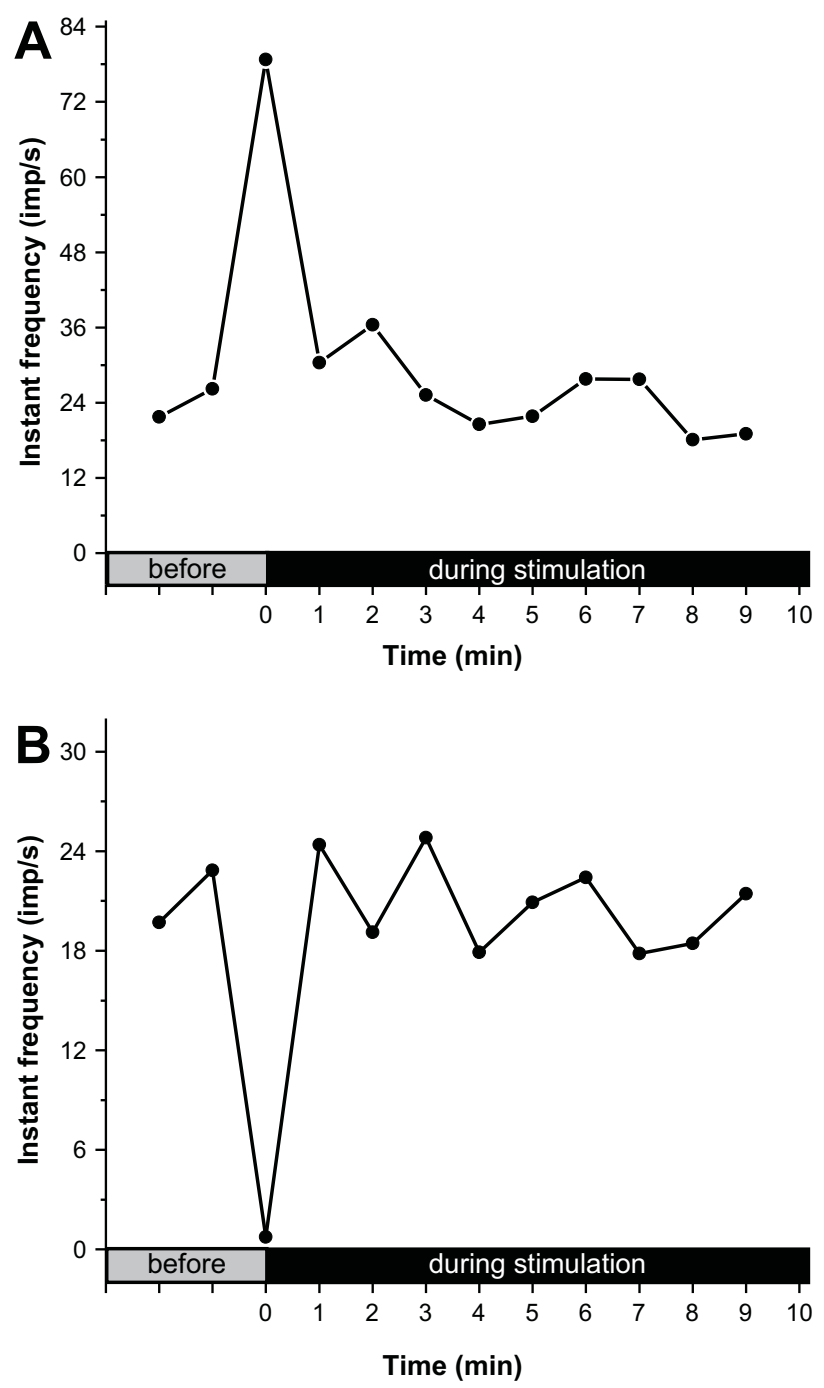

Fig. 8. Physiological adaptation of a cold-sensitive neuron to prolonged stimulation with a convective stimulus. A: During stimulation with cold air $\left(18^{\circ} \mathrm{C}\right)$ the coldsensitive neuron resumed to pre-stimulus activity within the first minute of stimulation. B: During stimulation with warm $\operatorname{air}\left(30^{\circ} \mathrm{C}\right)$, a similar result was found. This rapid adaptation was observed for all the cold-sensitive neurons investigated $(n=9)$.

$6 \mu \mathrm{m}$ into cuticle. Thermal energy is absorbed at the sensillum and the electron-dense filaments of the sensory peg might improve the absorption. If this is the case, the outermost cavity of the sensory peg is important for thermal stimulus transduction and the wall structure (double-walled) can be considered as adapted for thermoreception.

It has been shown in behavioral experiments that leaf-cutting ants are able to use radiant heat for orientation, an ability that requires the spatial detection of thermal objects (Kleineidam et al., 2007). Antennal scanning can be observed during this orientation task, and the $S$. coeloconica are good candidate sensilla to receive spatial information about the thermal environment.

\section{Acknowledgements}

This work was supported by the DFG, Germany (SFB 554, A6 and E1), DAAD (Vigoni D/05/54047) and CRUI (Vigoni 2005-2006). We thank Cesare Dentini (DSAA, Perugia University) who helped with the SEM and TEM experiments, as well as to Georg Krohne from the EM-facility of the Biozentrum. TEM data were obtained at the CUME, Perugia University; SEM and physiological data were obtained at the Biozentrum, University of Würzburg. We thank Rüdiger Wehner for fruitful discussions on the manuscript. We are indebted to Alejandro G. Di Giacomo and the Götz family for providing facilities and allowing the collection of leaf-cutting ants at the Reserva Ecológica El Bagual (Alparamis SA - Aves Argentinas) in Formosa, Argentina. We thank two anonymous reviewers who helped improving the manuscript.

\section{References}

Altner, H., Prillinger, L., 1980. Ultrastructure of invertebrate chemo-, thermo- and hygroreceptors and its functional significance. International Review of Cytology 6, 69-139.

Altner, H., Loftus, R., 1985. Ultrastructure and function of insect thermoreceptors and hygroreceptors. Annual Review of Entomology 30, 273-295.

Altner, H., Sass, H., Altner, I., 1977. Relationship between structure and function of antennal chemoreceptive, hygroreceptive, and thermoreceptive sensilla in Periplaneta americana. Cell and Tissue Research 176, 389-405.

Altner, H., Tichy, H., Altner, I., 1978. Lamellated outer dendritic segments of a sensory cell within a poreless thermoreceptive and hygroreceptive sensillum of insect Carausius morosus. Cell and Tissue Research 191, 287-304.

Altner, H., Routil, C., Loftus, R., 1981. The structure of bimodal chemoreceptive, thermoreceptive, and hygroreceptive sensilla on the antenna of Locusta migratoria. Cell and Tissue Research 215, 289-308.

Altner, H., Schaller-Selzer, L., Stetter, H., Wohlrab, I., 1983. Poreless sensilla with inflexible sockets - a comparative study of a fundamental type of insect sensilla probably comprising thermoreceptors and hygroreceptors. Cell and Tissue Research 234, 279-307.

Ameismeier, F., 1985. Embryonic development and molting of the antennal coeloconic no pore- and double-walled wall pore sensilla in Locusta migratoria (Insecta, Orthopteroidea). Zoomorphology 105, 356-366.

Ameismeier, F., Loftus, R., 1988. Response characteristics of cold cell on the antenna of Locusta migratoria. Journal of Comparative Physiology A 163, 507-516.

Boeckh, J., 1967. Reaction thresholds and specificity of an odor receptor on antenna of Locusta migratoria. Zeitschrift für Vergleichende Physiologie 55, 378-406.

Bollazzi, M., Roces, F., 2002. Thermal preference for fungus culturing and brood location by workers of the thatching grass-cutting ant Acromyrmex heyeri. Insectes Sociaux 49, 153-157.

Corbière-Tichané, G., 1977. Comparative study of ultrastructural morphology of vesicule olfactive of cave Catopidae (Coleoptera). Annales Des Sciences Naturelles-Zoologie Et Biologie Animale 19, 89-110.

Corbière, G., 1974. Fine-structure of an antennal sensory organ (vesicule-olfactive) of Speophyes lucidulus Delar (cave coleoptera of bathysciinae subfamily). Tissue \& Cell 6, 535-550

Corbière, G., Bermond, N., 1972. Comparative study on lamellated nervous structures in antenna of certain coleoptera - electron microscopical investigations. Zeitschrift für Zellforschung und Mikroskopische Anatomie 127, 9-33.

Cribb, B.W., Jones, M.K., 1995. Reappraisal of the pore channel system in the grooved pegs of Aedes aegypti. Tissue \& Cell 27, 47-53.

Davis, E.E., 1977. Response of antennal receptors of male Aedes aegypti mosquito. Journal of Insect Physiology 23, 613-617.

Davis, E.E., Sokolove, P.G., 1975. Temperature responses of antennal receptors of mosquito, Aedes aegypti. Journal of Comparative Physiology 96, 223-236.

Dumpert, K., 1972. Structure and distribution of sensilla on antennal flagellum of Lasius fuliginosus (Hymenoptera, Formicidae). Zeitschrift für Morphologie der Tiere 73, 95-116.

Dumpert, K., 1978. Das Sozialleben der Ameisen. Verlag Paul Parey, Berlin/Hamburg.

Evans, W.G., 1964. Infra-red receptors in Melanophila acuminata De Geer. Nature 202, 211.

Gingl, E., Tichy, H., 2001. Infrared sensitivity of thermoreceptors. Journal of Comparative Physiology A 187, 467-475.

Gingl, E., Hinterwirth, A., Tichy, H., 2005. Sensory representation of temperature in mosquito warm and cold cells. Journal of Neurophysiology 94, 176-185.

Gödde, J., Haug, T., 1990. Analysis of the electrical responses of antennal thermoreceptors and hygroreceptors of Antheraea (Saturniidae, Lepidoptera) to thermal, mechanical, and electrical Stimuli. Journal of Comparative Physiology A $167,391-401$.

Hansson, B.S., Ochieng, S.A., Grosmaitre, X., Anton, S., Njagi, P.G.N., 1996. Physiological responses and central nervous projections of antennal olfactory receptor neurons in the adult desert locust, Schistocerca gregaria (Orthoptera: Acrididae). Journal of Comparative Physiology A 179, 157-167.

Hashimoto, Y., 1990. Unique features of sensilla on the antennae of Formicidae (Hymenoptera). Applied Entomology and Zoology 25, 491-501.

Haug, T., 1986. Struktur, Funktion und Projektion der antennalen Thermo- und Hygrorezeptoren von Antheraea pernyi (Lepidoptera: Saturniidae). Thesis, Universitiy of Regensburg.

Hess, E., Loftus, R., 1984. Warm and cold receptors of 2 sensilla on the foreleg tarsi of the tropical bont tick Amblyomma variegatum. Journal of Comparative Physiology A 155, 187-195.

Hess, E., Loftus, R., 1985. Warm and cold receptors of 2 sensilla on the foreleg tarsi of Amblyomma variegatum (Acari, Ixodidae). Experientia 411221. 
Hunger, T., Steinbrecht, R.A., 1998. Functional morphology of a double-walled multiporous olfactory sensillum: the sensillum coeloconicum of Bombyx mori (Insecta, Lepidoptera). Tissue \& Cell 30, 14-29.

Itoh, T., Yokohari, F., Tominaga, Y., 1984. 2 types of antennal hygroreceptive and thermoreceptive sensilla of the cricket, Gryllus bimaculatus (De Geer). Zoological Science 1, 533-543.

Iwasaki, M., Itoh, T., Yokohari, F., Tominaga, Y., 1995. Identification of antennal hygroreceptive sensillum and other sensilla of the firefly, Luciola cruciata. Zoological Science 12, 725-732.

Jaisson, P.M., 1970. Note préliminaire sur le polymorphisme sensoriel et l'existence d'un nouveau type de sensillum chez la Fourmi champignoniste: Atta laevigata. Comptes Rendus de l'Académie des Sciences (Paris) 271, 1192-1194.

Kaissling, K.E., Strausfeld, C.Z., Rumbo, E.R., 1987. Adaptation processes in insect olfactory receptors - mechanisms and behavioral significance. Annals of the New York Academy of Sciences 510, 104-112.

Keil, T.A., 1997. Functional morphology of insect mechanoreceptors. Microscopy Research and Technique 39, 506-531.

Kleineidam, C., Tautz, J., 1996. Perception of carbon dioxide and other "air-condition" parameters in the leaf cutting ant Atta cephalotes. Naturwissenschaften 83, 566-568.

Kleineidam, C., Roces, F., 2000. Carbon dioxide concentrations and nest ventilation in nests of the leaf-cutting ant Atta vollenweideri. Insectes Sociaux 47, 241-248.

Kleineidam, C., Ernst, R., Roces, F., 2001. Wind-induced ventilation of the giant nests of the leaf-cutting ant Atta vollenweideri. Naturwissenschaften 88, 301-305.

Kleineidam, C., Romani, R., Tautz, J., Isidoro, N., 2000. Ultrastructure and physiology of the $\mathrm{CO}_{2}$ sensitive sensillum ampullaceum in the leaf-cutting ant Atta sexdens. Arthropod Structure \& Development 29, 43-55.

Kleineidam, C.J., Ruchty, M., Casero-Montes, Z.A., Roces, F., 2007. Thermal radiation as a learned orientation cue in leaf-cutting ants (Atta vollenweideri). Journal of Insect Physiology 53, 478-487.

Lacher, V., 1964. Elektrophysiologische Untersuchungen an einzelnen Rezeptoren für Geruch, Kohlendioxyd, Luftfeuchtigkeit und Temperatur auf den Antennen der Arbeitsbiene und der Drohne (Apis mellifera $L$ ). Zeitschrift für Vergleichende Physiologie 48, 587-623.

Lee, J.K., Selzer, R., Altner, H., 1985. Lamellated outer dendritic segments of a chemoreceptor within wall-pore sensilla in the labial palp pit organ of the butterfly, Pieris rapae L (Insecta, Lepidoptera). Cell and Tissue Research 240, 333-342.

Loftus, R., 1966. Cold receptor on antenna of Periplaneta americana. Zeitschrift für Vergleichende Physiologie 52, 380-385.

Loftus, R., 1968. Response of antennal cold receptor of Periplaneta americana to rapid temperature changes and to steady temperature. Zeitschrift für Vergleichende Physiologie 59, 413-455.

Loftus, R., Corbière-Tichané, G., 1981. Antennal warm and cold receptors of the cave beetle, Speophyes lucidulus delar, in sensilla with a lamellated dendrite 1 . Response to sudden temperature change. Journal of Comparative Physiology A $143,443-452$

McKemy, D.D., 2007. Temperature sensing across species. Pflugers Archiv-European Journal of Physiology 454, 777-791.

McKemy, D.D., Neuhausser, W.M., Julius, D., 2002. Identification of a cold receptor reveals a general role for TRP channels in thermosensation. Nature 416, 52-58.

Merivee, E., Vanatoa, A., Luik, A., Rahi, M., Sammelselg, V., Ploomi, A., 2003. Electrophysiological identification of cold receptors on the antennae of the ground beetle Pterostichus aethiops. Physiological Entomology 28, 88-96.

Müller, M., Olek, M., Giersig, M., Schmitz, H., 2008. Micromechanical properties of consecutive layers in specialized insect cuticle: the gula of Pachnoda marginata (Coleoptera, Scarabaeidae) and the infrared sensilla of Melanophila acuminata (Coleoptera, Buprestidae). The Journal of Experimental Biology 211, 2576-2583.

Must, A., Merivee, E., Mand, M., Luik, A., Heidemaa, M., 2006a. Electrophysiological responses of the antennal campaniform sensilla to rapid changes of temperature in the ground beetles Pterostichus oblongopunctatus and Poecilus cupreus (Tribe Pterostichini) with different ecological preferences. Physiological Entomology 31, 278-285.

Must, A., Merivee, E., Luik, A., Mand, M., Heidemaa, M., 2006b. Responses of antennal campaniform sensilla to rapid temperature changes in ground beetles of the tribe platynini with different habitat preferences and daily activity rhythms. Journal of Insect Physiology 52, 506-513.

Nishikawa, M., Yokohari, F., Ishibashi, T., 1985. The antennal thermoreceptor of the camel cricket, Tachycines asynamorus. Journal of Insect Physiology 31, 517-524.

Nishikawa, M., Yokohari, F., Ishibashi, T., 1992. Response characteristics of 2 types of cold receptors on the antennae of the cockroach, Periplaneta americana $L$. Journal of Comparative Physiology A 171, 299-307.

Pophof, B., 1997. Olfactory responses recorded from sensilla coeloconica of the silkmoth Bombyx mori. Physiological Entomology 22, 239-248.

Pophof, B., Stange, G., Abrell, L., 2005. Volatile organic compounds as signals in a plant-herbivore system: Electrophysiological responses in olfactory sensilla of the moth Cactoblastis cactorum. Chemical Senses 30, 51-68.
Prellinger, 1940. Champagnerpropfen- und Flaschenorgane bei den Ameisen. Mikrokosmos 33, 125-127.

Renthal, R., Velasquez, D., Olmos, D., Hampton, J., Wergin, W.P., 2003. Structure and distribution of antennal sensilla of the red imported fire ant. Micron 34, 405-413.

Roces, F., Kleineidam, C., 2000. Humidity preference for fungus culturing by workers of the leaf-cutting ant Atta sexdens rubropilosa. Insectes Sociaux 47, 348-350.

Rosenzweig, M., Brennan, K.M., Tayler, T.D., Phelps, P.O., Patapoutian, A., Garrity, P.A., 2005. The Drosophila ortholog of vertebrate TRPA1 regulates thermotaxis. Genes \& Development 19, 419-424.

Schmitz, A., Sehrbrock, A., Schmitz, H., 2007. The analysis of the mechanosensory origin of the infrared sensilla in Melanophila acuminata (Coeloptera; Buprestidae) adduces new insight into the transduction mechanism. Arthropod Structure \& Development 36, 291-303.

Schmitz, H., Bleckmann, H., 1997. Fine structure and physiology of the infrared receptor of beetles of the genus Melanophila (Coleoptera: Buprestidae). International Journal of Insect Morphology \& Embryology 26, 205-215.

Schmitz, H., Bleckmann, H., 1998. The photomechanic infrared receptor for the detection of forest fires in the beetle Melanophila acuminata (Coleoptera: Buprestidae). Journal of Comparative Physiology A 182, 647-657.

Schmitz, H., Trenner, S., 2003. Electrophysiological characterization of the multipolar thermoreceptors in the "fire-beetle" Merimna atrata and comparison with the infrared sensilla of Melanophila acuminata (both Coleoptera, Buprestidae). Journal of Comparative Physiology A 189, 715-722.

Schmitz, H., Bleckmann, H., Murtz, M., 1997. Infrared detection in a beetle. Nature 386, 773-774.

Schmitz, H., Schmitz, A., Bleckmann, H., 2000a. A new type of infrared organ in the Australian "fire-beetle" Merimna atrata (Coleoptera: Buprestidae). Naturwissenschaften $87,542-545$.

Schmitz, H., Murtz, M., Bleckmann, H., 2000b. Responses of the infrared sensilla of Melanophila acuminata (Coleoptera: Buprestidae) to monochromatic infrared stimulation. Journal of Comparative Physiology A 186, 543-549.

Schmitz, H., Schmitz, A., Trenner, S., Bleckmann, H., 2002. A new type of insect infrared organ of low thermal mass. Naturwissenschaften 89, 226-229.

Shanbhag, S.R., Singh, K., Singh, R.N., 1995. Fine structure and primary sensory projections of sensilla located in the sacculus of the antenna of Drosophila melanogaster. Cell and Tissue Research 282, 237-249.

Slifer, E.H., Sekhon, S.S., 1961. Fine structure of sense organs on antennal flagellum of honeybee, Apis mellifera linnaeus. Journal of Morphology 109, 351-380.

Steinbrecht, R.A., 1989. The fine structure of thermo hygrosensitive sensilla in the silkmoth Bombyx mori - Receptor membrane substructure and sensory cell contacts. Cell and Tissue Research 255, 49-57.

Steinbrecht, R.A., 1997. Pore structures in insect olfactory sensilla: a review of data and concepts. International Journal of Insect Morphology \& Embryology 26, 229-245.

Tichy, H., 1978. Hygroreceptor identification and response characteristics in the stick insect Carausius morosus. Journal of Comparative Physiology A 160, $33-42$.

Tichy, H., 1979. Hygro- and thermoreceptive triad in antennal sensillum of the stick insect, Carausius morosus. Journal of Comparative Physiology A 132, 149-152.

Tichy, H., 2007. Humidity-dependent cold cells on the antenna of the stick insect. Journal of Neurophysiology 97, 3851-3858

Tominaga, Y., Yokohari, F., 1982. External structure of the sensillum capitulum, a hygroreceptive and thermoreceptive sensillum of the cockroach, Periplaneta americana. Cell and Tissue Research 226, 309-318.

Vondran, T., Apel, K.H., Schmitz, H., 1995. The infrared receptor of Melanophila acuminata De Geer (Coleoptera: Buprestidae): ultrastructural study of a unique insect thermoreceptor and its possible descent from a hair mechanoreceptor. Tissue \& Cell 27, 645-658.

Waldow, U., 1970. Electrophysiological investigations of moist, dry and cold receptors on the antenna of the migratory locust. Zeitschrift für Vergleichende Physiologie 69, 249-283.

Weber, N.A., 1966. Fungus-growing ants. Science 153, 587-604.

Yokohari, F., 1978. Hygroreceptor mechanism in the antenna of the cockroach Periplaneta. Journal of Comparative Physiology 124, 53-60.

Yokohari, F., 1981. The sensillum capitulum, an antennal hygroreceptive and thermoreceptive sensillum of the cockroach, Periplaneta americana $L$. Cell and Tissue Research 216, 525-543.

Yokohari, F., 1983. The coelocapitular sensillum, an antennal hygroreceptive and thermoreceptive sensillum of the honeybee, Apis mellifera. Cell and Tissue Research 233, 355-365.

Yokohari, F., Tominaga, Y., Tateda, H., 1982. Antennal hygroreceptors of the honeybee, Apis mellifera L. Cell and Tissue Research 226, 63-73.

Zimmermann, B., 1992. Antennal thermosensitive and hygrosensitive sensilla in Antheraea pernyi (Lepidoptera, Saturniidae) - Ultrastructure and immunohistochemical localization of $\mathrm{Na}^{+}, \mathrm{K}^{+}$-ATPase. Cell and Tissue Research 270, 365-376. 